Published 5th october 2015

Journal Name

Journal of Materials Chemistry A 2015, 3, (45), 22931-22939

ARTICLE

\title{
Structural and microstructural characterization and properties of new phases in the Nd-Sr-Co-(Fe/Mn)-O system as air-electrodes in SOFCs
}

Received 00th January 20xx, Accepted 00th January 20xx

DOI: $10.1039 / x 0 x x 00000 x$

www.rsc.org/

\begin{abstract}
K. Boulahya, ${ }^{a}$ D. Muñoz Gil, ${ }^{a}$ M. Hassan, ${ }^{a}$ S. García Martin, ${ }^{a}$ U. Amador ${ }^{b, *}$
New oxides of the $(\mathrm{Nd}-\mathrm{Sr})_{n+1} \mathrm{MO}_{3 \mathrm{n}+1}(\mathrm{M}=\mathrm{Co}$ and $\mathrm{Mn}$ or $\mathrm{Fe})$ series are reported. Compounds of composition $\mathrm{NdSrCo}_{0.75} \mathrm{Fe}_{0.25} \mathrm{O}_{4.10}, \mathrm{NdSrCo}_{0.75} \mathrm{Mn}_{0.25} \mathrm{O}_{4.08}$ and $\mathrm{Nd}_{0.5} \mathrm{Sr}_{1.5} \mathrm{Co}_{0.75} \mathrm{Mn}_{0.25} \mathrm{O}_{3.86}$ are the $\mathrm{n}=1$ members of the Ruddlesden-Popper homologous series $\left(\mathrm{K}_{2} \mathrm{NiF}_{4}\right.$ structural type) as determined by $\mathrm{X}$-ray diffraction and different transmission electron microscopy techniques. Their crystal structure consist of connected (Co-Fe/Mn)O ${ }_{6}$ octahedra blocks separated by ( $\mathrm{Nd} / \mathrm{Sr}$ ) O rock-salt like layers along the c-axis. Interstitial oxygen atoms or anion vacancies are induced depending on composition. Oxides with interstitial oxygen show good performances as intermediate temperature solid oxide fuel cells (IT-SOFC) cathode. The area-specific resistance values of electrodes made of these oxides at $973 \mathrm{~K}$ in air are $0.18 \Omega \mathrm{cm}^{2}$ for $\mathrm{NdSrCO}{ }_{0.75} \mathrm{Fe}_{0.25} \mathrm{O}_{4.10}$ and $\mathrm{NdSrCO}_{0.75} \mathrm{Mn}_{0.25} \mathrm{O}_{4.08}$ (comparable to the one of state-of-the-art materials proposed as cathodes in IT-SOFC) and $1.38 \Omega \mathrm{cm}^{2}$ for $\mathrm{Nd}_{0.5} \mathrm{Sr}_{1.5} \mathrm{Co}_{0.75} \mathrm{Mn}_{0.25} \mathrm{O}_{3.86}$.
\end{abstract}

\section{Introduction}

Cobalt-containing oxides with perovskite-related structures, usually referred as cobaltites, are of paramount interest among the transition-metal oxides. Cobaltites display a huge variety of structural and physical properties due to the ability of Co ions to adopt several oxidation states as well as different spin states. ${ }^{1,2}$ Magnetic and electrical properties or a variety of types of catalytic activities make them promising materials for different applications. Thus, uncommon electrical behaviour is observed in the $\mathrm{La}_{1-\mathrm{x}} \mathrm{Sr}_{\mathrm{x}} \mathrm{CoO}_{3-\mathrm{y}}$ system ${ }^{3}, \mathrm{La}_{1-\mathrm{x}}(\mathrm{Ba}, \mathrm{Sr}, \mathrm{Ca})_{x} \mathrm{CoO}_{3-\mathrm{y}}$ presents giant magnetoresistance ${ }^{4}$ and thermoelectric power properties have been reported for $\mathrm{Ca}_{3} \mathrm{CO}_{4} \mathrm{O}_{9}{ }^{5}$

Among cobaltites, those oxides belonging to the RuddlesdenPopper (R-P) homologous series ${ }^{6,7}$ with the general formula $A_{n+1} B_{n} O_{3 n+1} \quad\left(\left(A B O_{3}\right)_{n} A O\right) \quad$ ( $A=$ Rare and/or alkaline earth elements and $B=$ transition metal), are especially interesting.

The crystal structure of the R-P series consist of n-octahedrathick perovskite-like blocks alternating with single $A O$ rock-salt layers. R-P cobaltites may present electronic conduction associated to the presence of mixed oxidation states of cobalt in the perovskites blocks. Even more, the discovery of high oxide-ionic conductivity in $A_{n+1} B_{n} O_{3 n+1}$ oxides has stimulated the search for new R-P materials with Mixed Ionic-Electronic Conductors (MIEC) for electrodes in Intermediate Temperature Solid Oxide Fuel Cells (IT-SOFCs). ${ }^{8-15}$ The interest of the R-P oxides as electrodes in IT-SOFCs has been mainly focused on

\footnotetext{
a. Departamento de Química Inorgánica, Facultad Ciencias Químicas, Universidad Complutense, E-28040 Madrid, Spain.

${ }^{b .}$ Departamento de Química, Facultad de Farmacia, Universidad CEU San Pablo, Urb. Montepríncipe, Boadilla del Monte, E-28668, Madrid, Spain. E-mail: uamador@ceu.es. Fax: +34-91-3510496

Electronic Supplementary Information (ESI) available: TGA plots, XRD data
}

materials with $\mathrm{K}_{2} \mathrm{NiF}_{4}$-like structure, which is the $\mathrm{n}=1$ member of the homologous series, where one-octahedron-thick perovskite layers alternate with single AO rock salt sheets along the packing axis, ${ }^{10-13}$ though there are some articles reporting the properties of $\mathrm{n}=2$ and 3 members. ${ }^{8,9}, 15$ Previous studies show that Co-based R-P oxides present high catalytic activity for oxygen reduction and high electronic conductivity but relatively high thermal expansion coefficients (TEC), as observed for Co-perovskites. Substitution of Co by $\mathrm{Cu}$ or Fe decreases TEC. ${ }^{9,11,16}$ On the other hand, it is well established that Sr-substitution for Ba increases the stability of perovskite-like oxides under ambient atmosphere containing $\mathrm{CO}_{2}$ and moisture. ${ }^{17}$

The knowledge of the relationships between structure and properties is crucial for the design of efficient materials. Therefore some members of the series $\mathrm{Sr}_{n+1} \mathrm{Co}_{n} \mathrm{O}_{3 n+1}$ have been subject of intensive structural-properties studies. It is found that oxygen hyperstoichiometric $\mathrm{K}_{2} \mathrm{NiF}_{4}$-type phases present higher ionic conductivity than anion deficient ones ${ }^{12}$ due to the oxygen interstitial migration in the rock-salt type layers of the structure ${ }^{18,19}$ Besides, octahedra rotation distortions play an important role in the oxide-ion migration of these materials. $^{20}$

In this study, new phases of the $\mathrm{n}=1$ member of $(\mathrm{Nd}, \mathrm{Sr})_{n+1} \mathrm{Co}_{n} \mathrm{O}_{3 n+1} \mathrm{R}-\mathrm{P}$ series as result of substitution of Co by $\mathrm{Fe}$ and $\mathrm{Mn}$ have been prepared. The general interest on the Co substitution by $\mathrm{Fe}$ and $\mathrm{Mn}$ is based on increasing thermal stability and decreasing TECs and cost of materials. A detailed structural characterization by $X$-ray diffraction and transmission electron microscopy has been performed to elucidate the crystal structure of these compounds with the aim of establishing some structure-properties relations. Besides, electrochemical properties of these materials have been explored. 


\section{Results and Discussion}

Samples of nominal compositions $\mathrm{NdSrCO}_{0.75} \mathrm{Fe}_{0.25} \mathrm{O}_{4}$ $\mathrm{NdSrCo} \mathrm{CO}_{0.75} \mathrm{Mn}_{0.25} \mathrm{O}_{4}$ and $\mathrm{Nd}_{0.5} \mathrm{Sr}_{1.5} \mathrm{Co}_{0.75} \mathrm{Mn}_{0.25} \mathrm{O}_{4}$ (labelled as NSCF7525, NSCM7525 and NSCM05157525, respectively) were confirmed to be single-phase by PXRD. The corresponding patterns (Fig. 1) can be fully indexed in a tetragonal unit cell with lattice parameters $\mathrm{a} \approx 3.80 \AA$ and $\mathrm{c} \approx 12.35 \AA$ and Space Group $14 / \mathrm{mmm}$. On its hand, thermal analyses (see Fig. 1 of Electronic Supplementary Information) revealed that the two first samples present interstitial oxygen atoms in a concentration close to 0.10 per formula unit, whereas the latter one exhibits no extra oxygen. Moreover, as the structural study suggests, this oxide seems to be oxygen deficient.
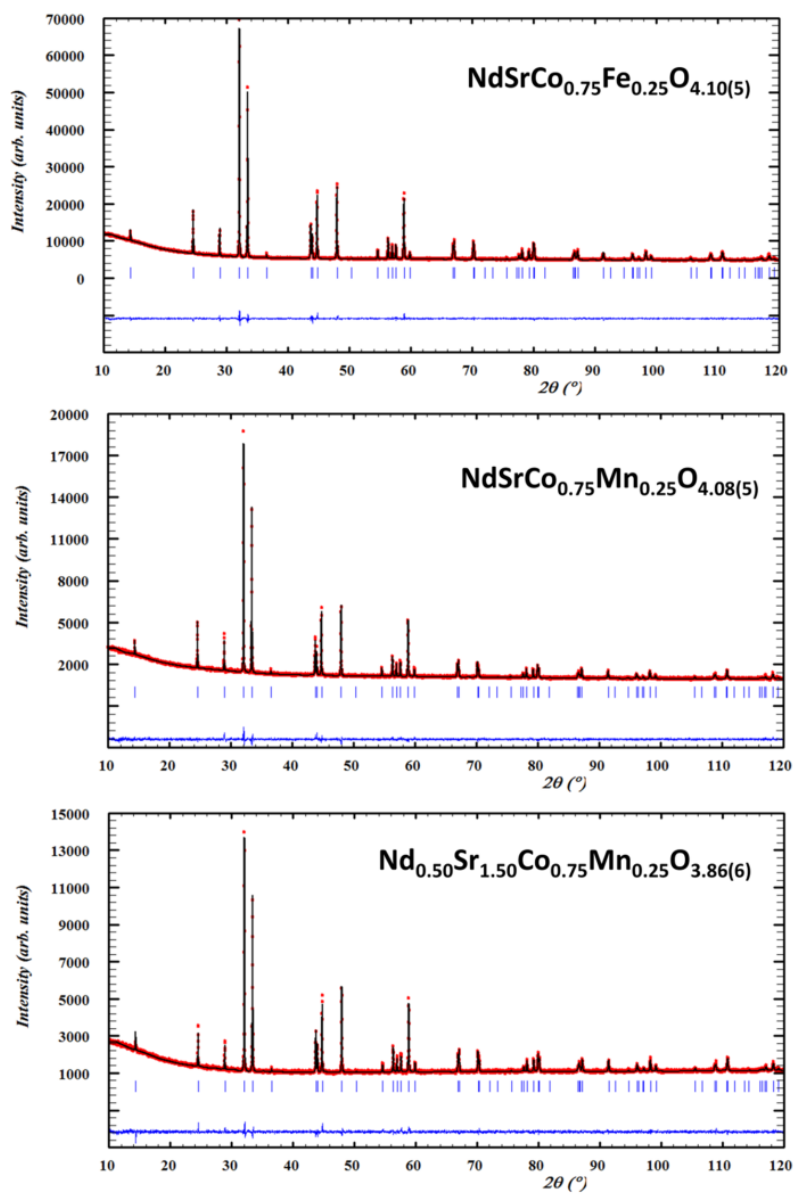

Figure 1: Graphic result of the fitting of the $\mathrm{X}$-ray diffraction patterns for $\mathrm{NdSrCo}_{0.75} \mathrm{Fe}_{0.25} \mathrm{O}_{4.10}, \mathrm{NdSrCo} \mathrm{Co}_{0.75} \mathrm{Mn}_{0.25} \mathrm{O}_{4.08}$ and $\mathrm{Nd}_{0.5} \mathrm{Sr}_{1.5} \mathrm{Co}_{0.75} \mathrm{Mn}_{0.25} \mathrm{O}_{3.86}$. The vertical bars indicate the positions of the Bragg peaks.

The Electron microscopy study revealed that all phases are isostructural with $\mathrm{Sr}_{2} \mathrm{CoO}_{4}{ }^{21}$

Figures $2 a$ and $2 b$ present the HRTEM images and the corresponding FFT taken on crystals of NSCF7525 along the zone-axes [001] and [010]. All the reflections in the FFTs can be indexed in the tetragonal lattice determined by PXRD $(a=3.8 \AA$ and $c=12.3 \AA$ ); moreover, the systematic absences confirm the symmetry observed by this technique.
The HRTEM micrograph taken along [001] (Figure 2a) suggests that the material is well-ordered: $d$-spacings of $3.8 \AA$ and $3.8 \AA$, corresponding to $d_{100}$ and $d_{010}$ respectively, are clearly observed all over the crystal. The HRTEM image taken along [010] (Figure 2b) gives more information: besides confirming the material is well-ordered, the contrast variation and the $d$ spacings of $3.8 \AA$ and $12.3 \AA$, corresponding to $d_{100}$ and $d_{001}$ respectively, provide important structural details.

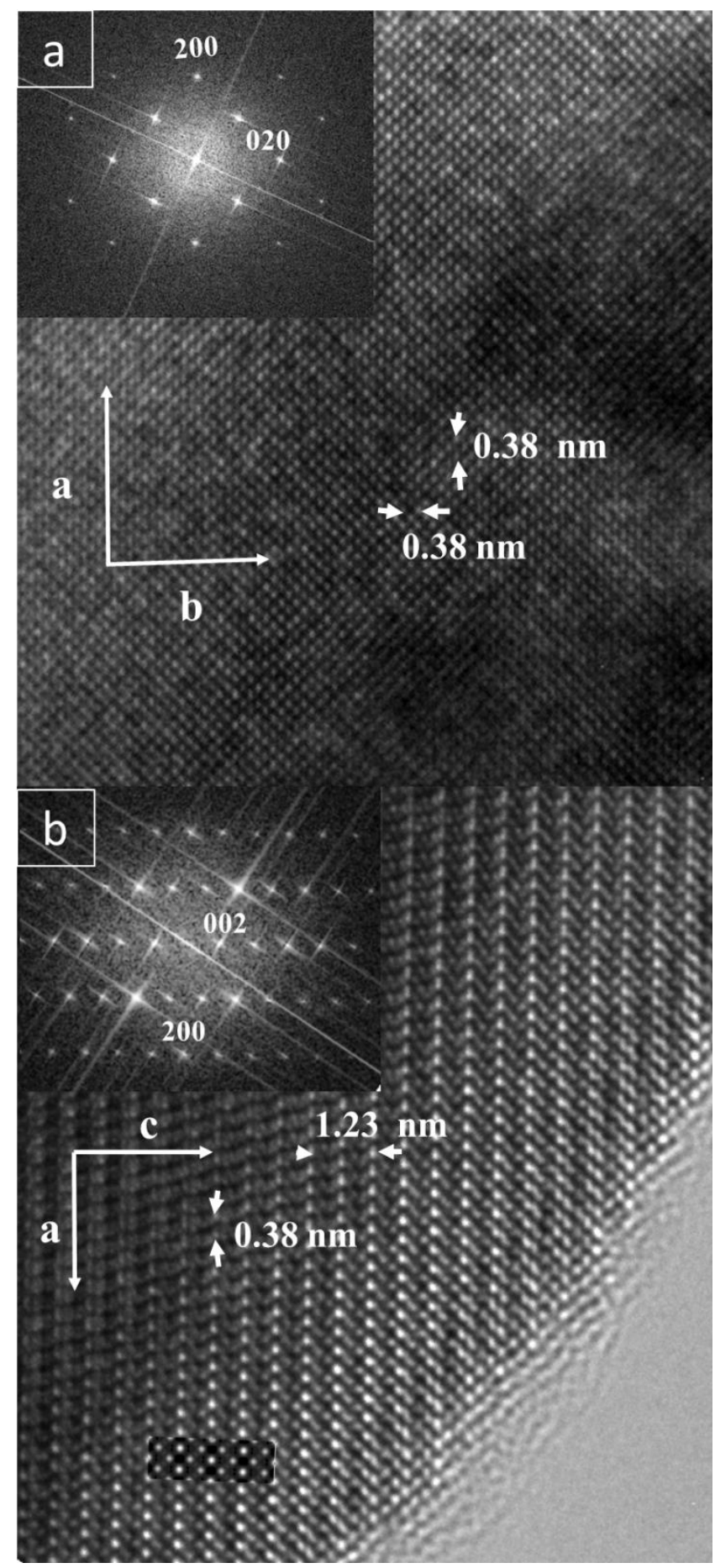

Figure 2: HRTEM image of $\mathrm{NdSrCO}_{0.75} \mathrm{Fe}_{0.25} \mathrm{O}_{4.10}$ along; (a) [001] and (b) [010] zone axis. Insets show the corresponding optical Fourier transform (FT) and simulated image. 
Thus, the contrast differences observed in this image correspond to two bright dots layers alternating with a less bright one, which can be associated to two Sr/Nd layers alternating with a $\mathrm{Co} / \mathrm{Fe}$ one along [001] as shown in the model depicted at a inset on Figure $2 b$. Such a contrast variation is characteristic of the $\mathrm{n}=1$ member of $\mathrm{R}-\mathrm{P}$ series as observed in the case of $\mathrm{Sr}_{n+1}\left(\mathrm{Co}, \mathrm{Ta}_{n} \mathrm{O}_{3 \mathrm{n}+1} \cdot{ }^{22,}{ }^{23}\right.$ There is no evidence of microdomains, neither extra spots nor diffuse scattering in the corresponding Fourier transforms of the HRTEM image (shown at the inset of Figure 2b), discarding any additional order.

NSCM7525 and NSCM05157525 compounds have been also studied by HRTEM. Figure 3a shows a HRTEM micrograph taken along the [010] zone axis of a crystal of NSCM7525; the material is well-ordered showing d-spacings of $3.9 \AA\left(\mathrm{d}_{100}\right)$ and $12.4 \AA\left(\mathrm{d}_{001}\right)$. As for the previous material, in this image along [001] two bright dot-layers alternate with a less bright one, which can be associated to two Sr/Nd layers and a Co one, respectively, as shown in the simulated image depicted at the inset of Figure 3a. Such a contrast variation corresponds to a $\mathrm{K}_{2} \mathrm{NiF}_{4}$-like structure ( $\mathrm{n}=1$ member of R-P series). No evidence of microdomains, or additional short-range order was observed in the corresponding Fourier transforms of the HRTEM images (shown at the inset of Figures 3a). Similar results were observed for NSCM05157525 (see Figure 3b).

Combining the information obtained by HRTEM and PXRD we have developed a structural model for the three oxides based on the structure of $\mathrm{Sr}_{2} \mathrm{CoO}_{4} \cdot{ }^{21,}{ }^{22}$ Fitting of the PXRD data confirms the validity of this model. The refinements were stable providing that the same Debye-Waller factor is used for each kind of atom (same for all the oxygens). Thus, it was possible to refine the positions and occupancies of all atoms, including oxygen atoms. Figure 1 shows the graphic results of the fitting of the experimental PXRD patterns and the difference between observed and calculated data. The final refined structural parameters are collected in Table 1, whereas Table 2 shows some selected interatomic distances. The structure refinement confirms that all compounds are isostructural with $\mathrm{Sr}_{2} \mathrm{CoO}_{4}{ }^{21}$ in agreement with the HRTEM results. In Figure 4, a schematic representation of the crystal structure is depicted.

Although X-ray diffraction is not the best technique to study structural details related to light atoms such as oxygen, our results seem to suggest the existence of some anion vacancies in NSCM05157525. On the contrary, it was not possible to locate the extra oxygen determined by TGA (see Fig. 1 of ESI) in NSCF7525, NSCM7525. Interestingly, the bond valence sums (BVS) for the 3d-metals agrees with the existence of some extra oxygen in these two latter oxides whereas for NSCM05157525 the actual refined oxygen content of 3.86(6) nicely agrees with the BVS determined for the 3d-ions.

\section{Electrochemical performance}

Chemical stability and compatibility with the electrolyte
Prior to the electrochemical measurements, the chemical stability of the materials and their compatibility with the electrolyte (CGO) were evaluated. These materials present a good stability in open atmosphere since the absence of $\mathrm{Ba}$ prevents their reaction with moisture and $\mathrm{CO}_{2}$. On the other hand, these oxides do not react with CGO: in the PXRD pattern of a mixture of a given material with CGO (70:30 wt \%) heated at $1173 \mathrm{~K}$ for 12 hours (Figure 5) only the Bragg maxima due to these two components are observed, discarding any reaction or decomposition.

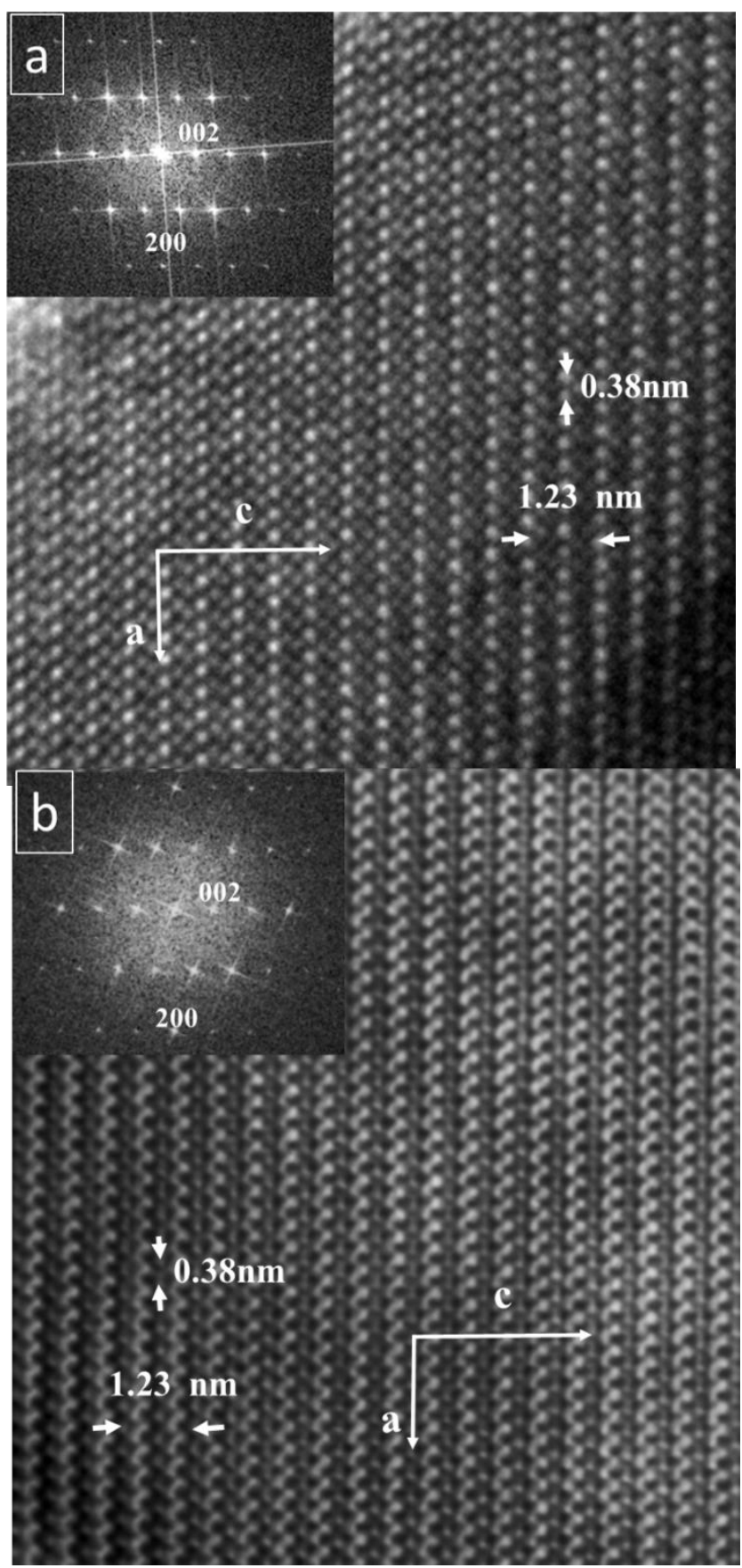

Figure 3: HRTEM image along [010] of crystal of (a) $\mathrm{NdSrCo}_{0.75} \mathrm{Mn}_{0.25} \mathrm{O}_{4.08}$ and (b) $\mathrm{Nd}_{0.5} \mathrm{Sr}_{1.5} \mathrm{Co}_{0.75} \mathrm{Mn}_{0.25} \mathrm{O}_{3.86}$ compounds. Insets show the corresponding optical Fourier transforms (FT). 


\section{Journal Name}

\section{ARTICLE}

Table 1: Structural parameters for $\mathrm{NdSrCo}_{0.75} \mathrm{Fe}_{0.25} \mathrm{O}_{4.10}, \mathrm{NdSrCo}_{0.75} \mathrm{Mn}_{0.25} \mathrm{O}_{4.08}$ and $\mathrm{Nd}_{0.5} \mathrm{Sr}_{1.5} \mathrm{Co}_{0.75} \mathrm{Mn}_{0.25} \mathrm{O}_{3.86}$ obtained from XRD data.

$\mathrm{NdSrCO} 0.75 \mathrm{Fe}_{0,25} \mathrm{O}_{4,10}$

a $(\AA)$

$c(\AA)$

$\mathrm{V}\left(\AA^{3}\right)$

$\mathrm{Nd} / \mathrm{Sr}$ position $4 \mathrm{e}$

Occ. $\mathrm{Nd} / \mathrm{Sr}$

$\mathrm{U} * 100\left(\AA^{2}\right)$

Co position $2 \mathrm{a}$

Occ. $\mathrm{Co} / \mathrm{M}$

$\mathrm{U} * 100\left(\AA^{2}\right)$

$\mathrm{O}(1)$ position $4 \mathrm{c}$

Occ.

$\mathrm{U} * 100\left(\AA^{2}\right)$

$\mathrm{O}(2)$ position $4 \mathrm{e}$

z

Occ.

U*100 $\left(\AA^{2}\right)$

${ }^{\mathrm{a}}$ Space Group 14/mnm (\#139): 2a (000), 4c (1/2 00 ), 4e (0 0 z

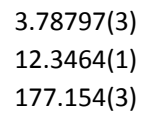

$\mathrm{NdSrCO}_{0.75} \mathrm{Mn}_{0.25} \mathrm{O}_{4.08}$

$\mathrm{Nd}_{0.50} \mathrm{Sr}_{1.50} \mathrm{Co}_{0.75} \mathrm{Mn}_{0.25} \mathrm{O}_{3.86}$

${ }^{\mathrm{b}} \chi^{2}=1.93, R_{\mathrm{wp}}=1.80 \%, \mathrm{R}_{\mathrm{exp}}=1.30 \%, \mathrm{R}_{\mathrm{B}}=1.58 \%$

${ }^{c} \chi^{2}=1.31, R_{w p}=3.13 \%, R_{\text {exp }}=2.74 \%, R_{B}=3.48 \%$

${ }^{d} \chi^{2}=1.40, R_{w p}=3.32 \%, R_{\exp }=2.80 \%, R_{B}=3.97 \%$

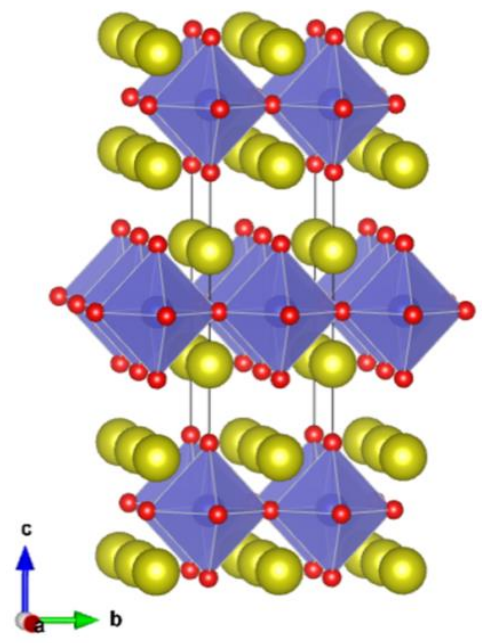

Figure 4: Schematic representation of the structure of $\mathrm{Sr}_{2} \mathrm{CoO}_{4}$ along the [100] direction: $\mathrm{Sr}(\mathrm{Nd})$ as large yellow balls, Co-Fe/Mn (3d-metal) in the centre of the octahedra and oxygen atoms as small red balls at the octahedra vertices.

Figure 6 displays the impedance spectra recorded in air at 973 $\mathrm{K}$ of symmetrical cells using NSCF7525, prepared by ceramic or sol-gel methods, as electrode materials with $\mathrm{Ce}_{0.9} \mathrm{Gd}_{0.1} \mathrm{O}_{2-\delta}$ (CGO) electrolyte. Lower ASR values are obtained for cells using the material prepared by sol-gel method. This is probably associated to differences in particle size (Figure 7), in such a way that smaller particle size produces larger surface contact between electrode and electrolyte. Consequently, increasing of triple phase boundaries (TPB) results in better electrochemical performances. ${ }^{24}$

Figure 8 shows the ASR values at different temperatures of symmetrical cells using the three compounds as electrodes. The substitution of Fe or $\mathrm{Mn}$ by $\mathrm{Co}$ in $\mathrm{NdSrCo}_{1-x} \mathrm{M}_{\mathrm{x}} \mathrm{O}_{4 \pm \delta}(\mathrm{M}=\mathrm{Fe}$, $\mathrm{Mn}$ ) seems not to affect to the ASR values. Besides, the activation energies are close for all samples, suggesting that the processes involved in oxygen reduction are similar in all of them. On the other hand, the $\mathrm{Sr}$ content seems to have an important influence, since the material with higher $\mathrm{Sr}$ concentration shows higher ASR values. This is most likely due to the absence of interstitial oxygen and the formation of some anion vacancies. Finally, it must be stressed that the lowest ASR values are obtained in cells prepared with materials showing extra oxygen, $\mathrm{NdSrCO}_{0.75} \mathrm{Fe}_{0.25} \mathrm{O}_{4.10}$ or $\mathrm{NdSrCO}_{0.75} \mathrm{Mn}_{0.25} \mathrm{O}_{4.08}$, prepared by sol-gel method. 
Table 2: Selected structural information for $\mathrm{NdSrCo}_{0.75} \mathrm{Fe}_{0.25} \mathrm{O}_{4.10}, \mathrm{NdSrCo} \mathrm{Co}_{0.75} \mathrm{Mn}_{0.25} \mathrm{O}_{4.08}$ and $\mathrm{Nd}_{0.5} \mathrm{Sr}_{1.5} \mathrm{Co}_{0.75} \mathrm{Mn}_{0.25} \mathrm{O}_{3.86}$ obtained from XRD data. Angles are given in degrees and distances in $\AA$. Distortion $\Delta$ of the $\mathrm{BO}_{\mathrm{n}}$ polyhedra is given as $\Delta=1 / \mathrm{n} \sum_{\mathrm{j}=1, \mathrm{n}}\left\{\left(\mathrm{d}_{\mathrm{n}}-<\mathrm{d}(\mathrm{B}-\mathrm{O})>\right) /<\mathrm{d}(\mathrm{B}-\mathrm{O})>\right\}^{2}$

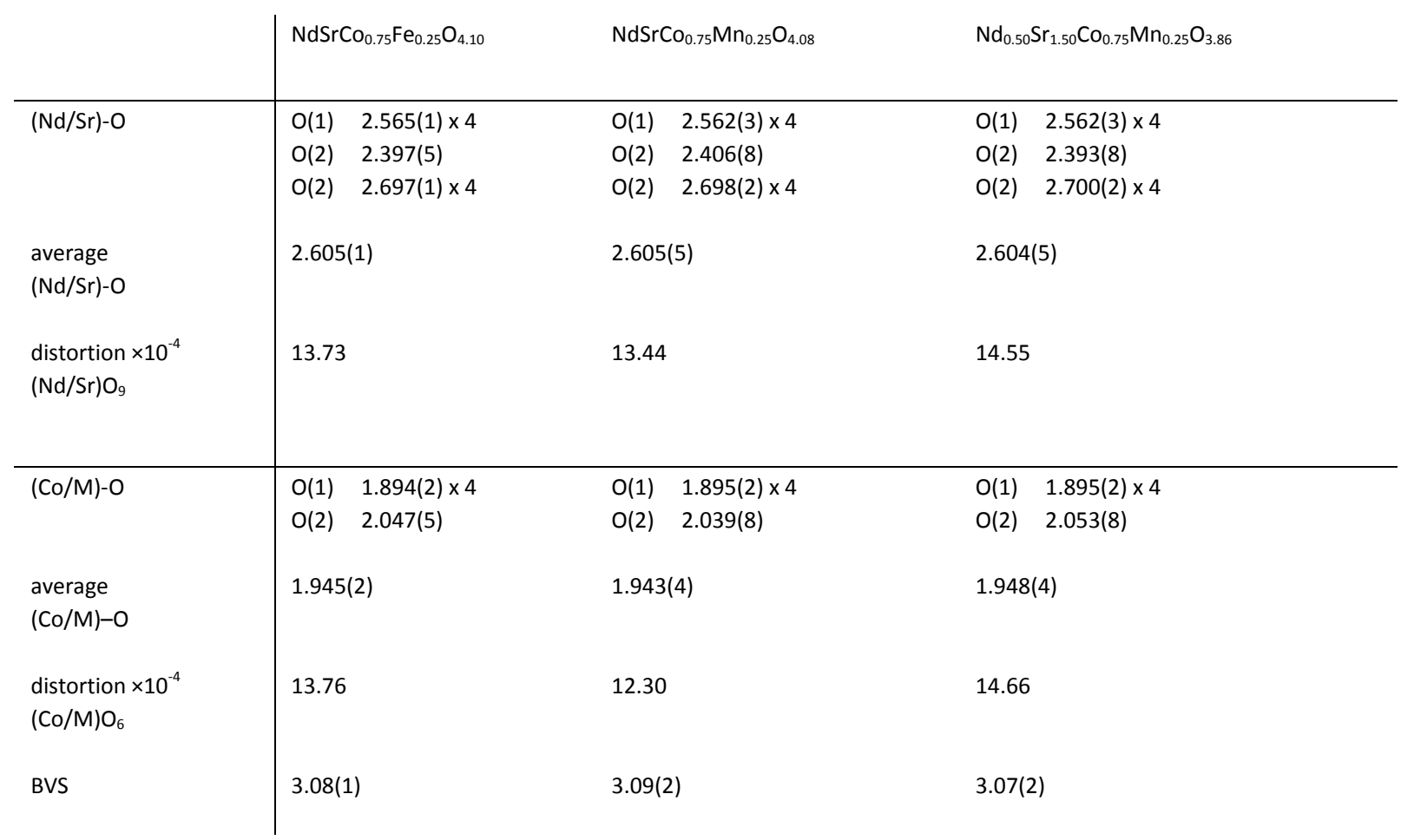
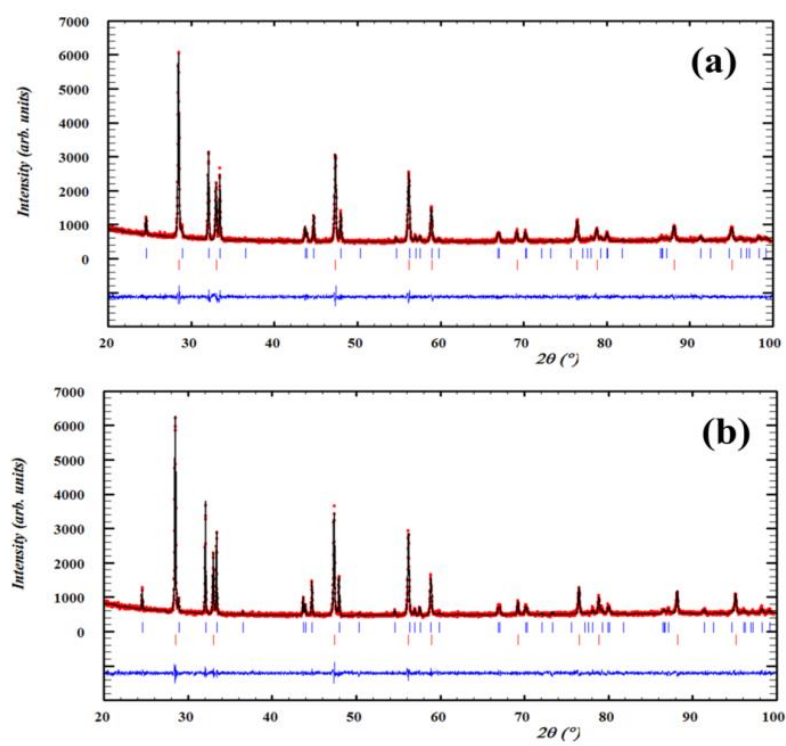

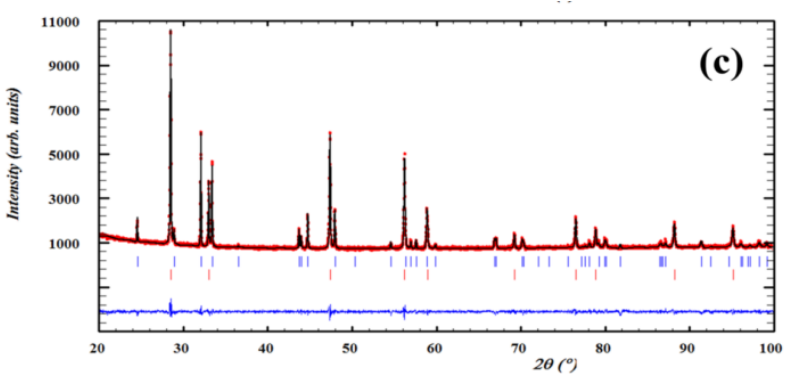

Figure 5: PXRD patterns of composites (70:30 wt\%) of (a) $\mathrm{NdSrCo}_{0.75} \mathrm{Fe}_{0.25} \mathrm{O}_{4.10}: \mathrm{CGO}$, (b) $\mathrm{NdSrCo} \mathrm{Co}_{0.75} \mathrm{Mn}_{0.25} \mathrm{O}_{4.08}: \mathrm{CGO}$ and (c) $\mathrm{Nd}_{0.5} \mathrm{Sr}_{1.5} \mathrm{Co}_{0.75} \mathrm{Mn}_{0.25} \mathrm{O}_{3.86}: \mathrm{CGO}$, treated in air at $900 \mathrm{C}$. The first row of vertical bars indicates the positions of Bragg reflections of the given material whereas the second row corresponds to the peaks of CGO. 


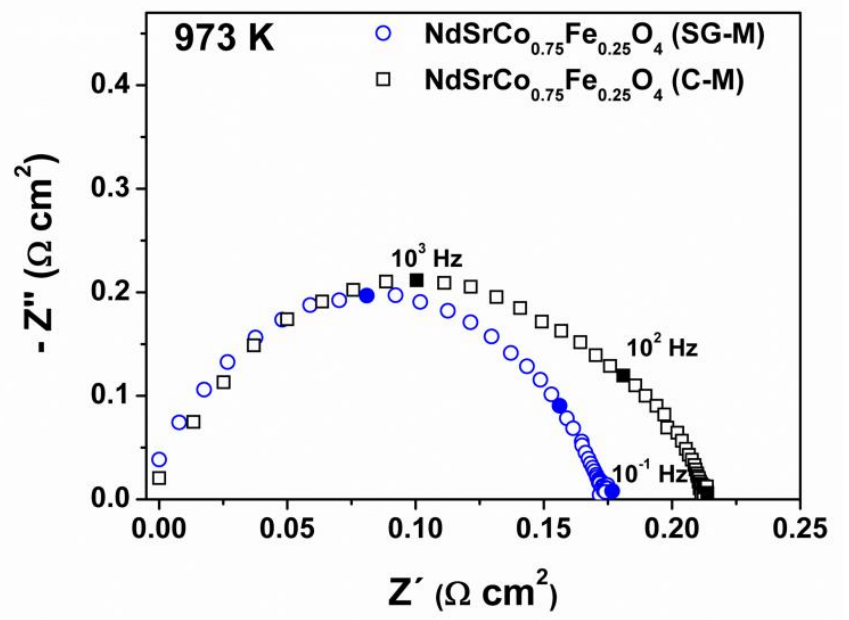

Figure 6: Impedance spectra of the NSCF7525(SG-M):CGO/CGO/NSCF7525(SG-M):CGO and NSCF7525(C-M):CGO/CGO/NSCF7525(C-M):CGO (SG-M and C-M denote sol-gel and ceramic methods, respectively) symmetrical cells at $973 \mathrm{~K}$ in air.

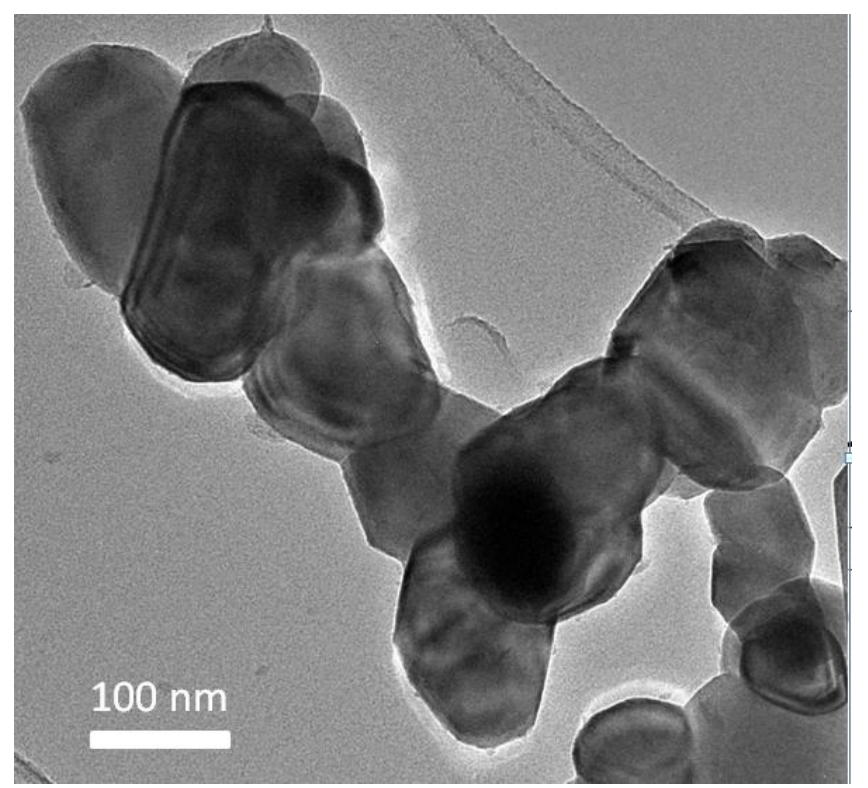

Figure 7: Low magnification TEM image of NSCF7525 nanoparticles synthetized by a sol-gel method.

Generally speaking, the most promising conducting materials present perovskite or $\mathrm{K}_{2} \mathrm{NiF}_{4}$ structure types, and contain one or a combination of transition-metal elements such as $\mathrm{Fe}, \mathrm{Co}$, $\mathrm{Ni}$ or $\mathrm{Cu}$. Electronic conduction in these two kinds of oxides is related to metals in intermediated (mixed) oxidation states. On the other hand, the ionic conduction mechanism occurs in two different ways: by motion of interstitial oxygen-anions contained into the $\mathrm{NaCl}$-like layers or by migration of oxygen vacancies in the perovskite blocks. ${ }^{9,11,19,25}$

In our case, the best ASR values (at $973 \mathrm{~K}$ ) were obtained for $\mathrm{NdSrCo}_{0.75} \mathrm{Fe}_{0.25} \mathrm{O}_{4.10}$ and $\mathrm{NdSrCo}_{0.75} \mathrm{Mn}_{0.25} \mathrm{O}_{4.08}$ (ca. $0.18 \Omega . \mathrm{cm}^{2}$ in both cases) probably associated to the existence of interstitial oxygen-anions. Similar values are only obtained at $1073 \mathrm{~K}$ for $\mathrm{La}_{4} \mathrm{Ni}_{2.6} \mathrm{Co}_{0.4} \mathrm{O}_{10+\delta}{ }^{8}$ and $\mathrm{NdSrCoO}_{4+\delta}{ }^{11}$ The loss of interstitial oxygen atoms seems to reduce the total conductivity resulting in larger ASR values, as observed for
$\mathrm{Nd}_{0.5} \mathrm{Sr}_{1.5} \mathrm{Co}_{0.75} \mathrm{Mn}_{0.25} \mathrm{O}_{3.86}$ for which an ASR of $1.38 \Omega . \mathrm{cm}^{2}$ was obtained (at $973 \mathrm{~K}$ ). In this context, the oxygen diffusion coefficient in $\mathrm{Nd}_{2} \mathrm{NiO}_{4+} \delta$, determined from isotopic exchange experiments, evidences that mobility of interstitial oxygen atoms is one to two orders of magnitude larger than that due to vacancies 3D-migration in perovskite-type oxides. ${ }^{18}$

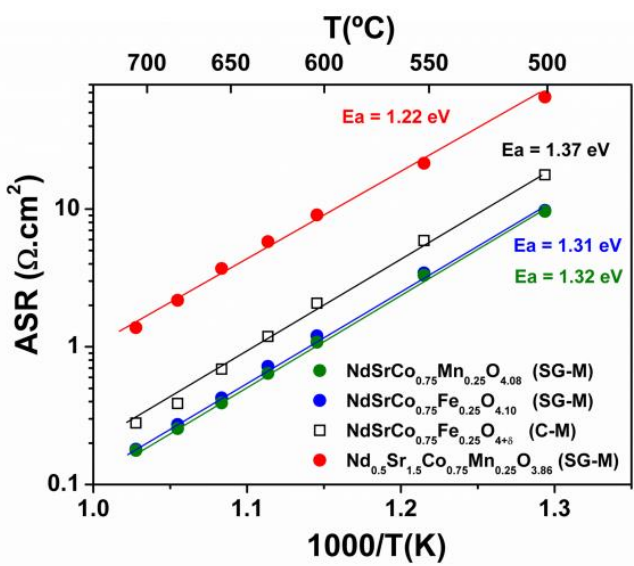

Figure 8: Arrhenius plots of the area-specific resistance (ASR) values vs $1000 / T$ of symmetrical cells using the three compounds as electrodes.

\section{Conclusions}

Oxides with composition $(\mathrm{Sr}, \mathrm{Nd})_{2} \mathrm{Co}_{0.75} \mathrm{M}_{0.25} \mathrm{O}_{4 \pm \delta} \quad(\mathrm{M}=\mathrm{Fe}$ and $\mathrm{Mn}$ ) have been prepared as single-phase materials showing $\mathrm{K}_{2} \mathrm{NiF}_{4}$-type crystal structure. The absence of the very basic ions $\mathrm{Ba}^{2+}$ in these materials provides a good stability at ambient conditions. Besides, they are chemically compatible with the electrolyte CGO at high temperatures. Importantly, they present good electrochemical activity for the reduction of oxygen at intermediate temperatures. The best performance in symmetrical cells has been obtained in the specimens with interstitial oxygen $\mathrm{SrNdCO}_{0.75} \mathrm{M}_{0.25} \mathrm{O}_{4.08} \quad(\mathrm{M}=\mathrm{Fe}$ and $\mathrm{Mn}$ ) prepared by sol-gel method. These compounds exhibited ASR values close to $0.18 \Omega \mathrm{cm}^{2}$ at $973 \mathrm{~K}$ which is a value comparable to those of state-of-the-art materials. Even more, the partial substitution of $\mathrm{Co}$ by $\mathrm{Mn}$ or $\mathrm{Fe}$ is expected to reduce the large TEC observed in cobaltites, which is a serious drawback for their use in real devices.

Therefore, the sol gel synthetized $\mathrm{SrNdCO}_{0.75} \mathrm{M}_{0.25} \mathrm{O}_{4.08}(\mathrm{M}=\mathrm{Fe}$ and $\mathrm{Mn}$ ) oxides emerge as promising materials for applications as air electrodes in IT-SOFCs.

\section{Experimental}

Polycrystalline samples of nominal compositions $\mathrm{NdSrCO}_{0.75} \mathrm{Fe}_{0.25} \mathrm{O}_{4}, \quad \mathrm{NdSrCO}_{0.75} \mathrm{Mn}_{0.25} \mathrm{O}_{4} \quad$ and $\mathrm{Nd}_{0.50} \mathrm{Sr}_{1.50} \mathrm{Co}_{0.75} \mathrm{Mn}_{0.25} \mathrm{O}_{4}$ (labelled as NSCF7525, NSCM7525 and NSCM05157525, respectively) were synthesized by solid state reaction and a modified Pechini method. ${ }^{26}$ Homogeneous single phase samples were obtained by the latter one. For the ceramic method, stoichiometric amounts of $\mathrm{SrCO}_{3}$ (Aldrich 99.98\%), $\mathrm{Co}_{3} \mathrm{O}_{4}$ (Aldrich 99.9\%), $\mathrm{Fe}_{2} \mathrm{O}_{3}$ (99\%), $\mathrm{MnO}_{2}$ and $\mathrm{Nd}_{2} \mathrm{O}_{3}$ (Aldrich 99+\%) were heated in air at $1273 \mathrm{~K}$ for several days (3- 
7), and then quenched to room temperature. For Pechini method, $\mathrm{Sr}\left(\mathrm{NO}_{3}\right)_{2}(99 \%), \mathrm{Nd}\left(\mathrm{NO}_{3}\right)_{3} \cdot 9 \mathrm{H}_{2} \mathrm{O}(99 \%), \mathrm{Co}\left(\mathrm{NO}_{3}\right)_{2} \cdot 6 \mathrm{H}_{2} \mathrm{O}$ (99\%), $\mathrm{Fe}\left(\mathrm{NO}_{3}\right)_{3} \cdot 9 \mathrm{H}_{2} \mathrm{O}$ (99\%), $\mathrm{Mn}\left(\mathrm{NO}_{3}\right)_{2} \cdot 6 \mathrm{H}_{2} \mathrm{O}$ (99\%) were solved in water. Citric acid was added while heating and stirring in a citric-acid-to-metal-ions molar ratio of 3:1. Polymerization was induced by adding ethylene glycol $(5 \mathrm{~mL})$ yielding a viscous resin. This resin was decomposed by heating until ashes were formed. To remove organic matter this powder was burned at $1073 \mathrm{~K}$; after this treatment the resulting powder was milled and fired in air at $1273 \mathrm{~K}$ for several hours (5-7), and then quenched to room temperature.

Powder X-ray diffraction (PXRD) has been used to check the purity of the samples and for crystal structure characterization. The data were collected on a Bruker D8 high-resolution monochromatic diffractometer. A $\operatorname{CuK}_{\alpha 1}(\lambda=1.5406 \AA)$ beam is obtained by a primary germanium monochromator); the diffractometer is equipped with a LynxEye ${ }^{\circledR}$ fast detector. The angular range, step size and counting times were selected to ensure that the experimental data have good statistics and high resolution suitable for structural refinement. Diffraction data were analysed using the Fullprof software; ${ }^{27}$ peak shape was described by a pseudo-Voigt function and the background level was fitted by linear interpolation.

Thermogravimetric analyses (TGA) in air have been performed in an SDT Q600 thermogravimetric analyser to determine the oxygen stoichiometry and stability of the oxides from room temperature to $1173 \mathrm{~K}$.

The compounds were characterized by High Resolution Transmission Electron Microscopy (HRTEM) on a JEOLJEM$3000 \mathrm{~F}$ electron microscope working at $300 \mathrm{kV}$. Local compositions were determined by energy-dispersive $\mathrm{X}$-ray spectroscopy (EDS) with an INCA Oxford analyser system attached to above mentioned electron microscopes.

The electrochemical performance of the title materials has been evaluated by Impedance Spectroscopy (IS). The areaspecific resistances (ASR) associated to the total electrochemical processes at the electrodes have been determined from the impedance diagrams at different temperatures in air on symmetrical two-electrode configuration cells. Pellets of the electrolyte (commercial $\mathrm{Ce}_{0.9} \mathrm{Gd}_{0.1} \mathrm{O}_{2-\delta}(\mathrm{CGO})$ powder (Fuel Cells Materials)) of about 8.6 $\mathrm{mm}$ diameter and $1.10 \mathrm{~mm}$ thickness were prepared by pressing the powder at $250 \mathrm{MPa}$ and sintering in air at $1673 \mathrm{~K}$ for 12 hours (heating/cooling rate of $2.5 \mathrm{~K} \mathrm{~min}^{-1}$ ). Thin layers of slurries prepared with $(\mathrm{Nd}, \mathrm{Sr}) \mathrm{Co}_{0.75} \mathrm{M}_{0.25} \mathrm{O}_{4 \pm \delta} / \mathrm{CGO}$ composite (70:30 wt \%) using Decoflux ${ }^{\mathrm{TM}}$ as a binder were deposited onto both surfaces of the electrolyte and then fired at $1173 \mathrm{~K}$ for $3 \mathrm{~h}$ in air (heating/cooling rate of $2.5 \mathrm{~K} \mathrm{~min}^{-1}$ ). Silver paste and silver mesh were used as current collectors attached by firing at $873 \mathrm{~K}$ for 2 hours (heating/cooling rate of $2.5 \mathrm{~K} \mathrm{~min}^{-1}$ ). The impedance spectra were obtained on heating and cooling cycles in the temperature range $773 \mathrm{~K}$ to $973 \mathrm{~K}$ using a frequency response analyser (Solartron $1255+$ dielectric interface 1296) in the frequency range $0.1 \mathrm{~Hz}$ to 1 $\mathrm{MHz}$ with an excitation voltage of $50 \mathrm{mV}$. The area-specific resistances (ASR) of the electrodes have been determined from raw impedance spectra by subtracting $x$-axis interceptions at low frequency from the corresponding values at high-frequency and corrected for the electrode area and divided by 2 , as it is common in symmetrical cells. ${ }^{24,28}$

Chemical compatibility of the studied compounds with the CGO was proven prior to the electrochemical studies by treating mixtures of these materials with CGO (70:30 wt \%) at $1173 \mathrm{~K}$ for 12 hours which were further analysed by PXRD.

\section{Acknowledgements}

We thank the Ministerio de Economía y Competitividad (MINECO) and Comunidad de Madrid for funding the projects MAT2013-46452-C4-1-R and MAT2013-46452-C4-4-R, and S2013/MIT-2753, respectively.

\section{Notes and references}

1. K. Boulahya, M. Hassan, J. C. G. Minguez and S. Nicolopoulos, Microsc. Microanal. , 2014, 20, 687-691.

2. G. Radtke and G. A. Botton, Scanning Transmission Electron Microscopy Imaging and Analysis, Springer Science Business Media, New York, 2011.

3. A. N. Petrov, O. F. Kononchuk, A. V. Andreev, V. A. Cherepanov and P. Kofstad, Solid State Ionics, 1995, 80, 189-199.

4. G. Briceno, H. Y. Chang, X. D. Sun, P. G. Schultz and X. D. Xiang, Science, 1995, 270, 273-275.

5. A. C. Masset, C. Michel, A. Maignan, M. Hervieu, O. Toulemonde, F. Studer, B. Raveau and J. Hejtmanek, Physical Review B, 2000, 62, 166-175.

6. S. N. Ruddlesden and P. Popper, Acta Crystallographica, 1958, 11, 54-55.

7. S. N. Ruddlesden and P. Popper, Acta Crystallographica, 1957, 10, 538-540.

8. G. Amow, J. Au and I. Davidson, Solid State Ionics, 2006, 177, 1837-1841.

9. K. T. Lee, D. M. Bierschenk and A. Manthiram, Journal of the Electrochemical Society, 2006, 153, A1255-A1260.

10. A. Aguadero, J. A. Alonso, M. J. Escudero and L. Daza, Solid State lonics, 2008, 179, 393-400.

11. K. W. Song and K. T. Lee, Ceramics International, 2011, 37, 573-577.

12. J. A. Kilner and M. Burriel, Annual Review of Materials Research, 2014, 44, 365-393.

13. G. N. Mazo, S. M. Kazakov, L. M. Kolchina, A. V. Morozov, S. Y. Istomin, N. V. Lyskov, A. A. Gippius and E. V. Antipov, Journal of Alloys and Compounds, 2015, 639, 381-386.

14. X. Huang, T. H. Shin, J. Zhou and J. T. S. Irvine, Journal of Materials Chemistry A, 2015, 3, 13468-13475.

15. K. Boulahya, M. Hassan, D. Muñoz-Gil, J. Romero, A. Gómez-Herrero, S. García-Martín and U. Amador, J. Mater. Chem. A. , 2015, 3, 22931-22939.

16. M. Al Daroukh, V. V. Vashook, H. Ullmann, F. Tietz and I. Arual Raj, Solid State Ionics, 2003, 158, 141-150.

17. I. M. Hung, H.-W. Peng, S.-L. Zheng, C.-P. Lin and J.-S. Wu, Journal of Power Sources, 2009, 193, 155-159.

18. J.-M. Bassat, M. Burriel, O. Wahyudi, R. Castaing, M. Ceretti, P. Veber, I. Weill, A. Villesuzanne, J.-C. Grenier, W. Paulus and J. A. Kilner, The Journal of Physical Chemistry C, 2013, 117, 26466-26472. 
19. V. V. Kharton, A. P. Viskup, A. V. Kovalevsky, E. N. Naumovich and F. M. B. Marques, Solid State lonics., 2001, 143, 337-353.

20. X. Li and N. A. Benedek, Chemistry of Materials, 2015, 27, 2647-2652.

21. J. Kim, A. Kagedan, G. D. Gu, C. S. Nelson and Y.-J. Kim, Phys. Rev. B. , 2008, 77, 180513.

22. K. Boulahya, M. Parras and J. M. Gonzalez-Calbet, European Journal of Inorganic Chemistry, 2007, DOI: 10.1002/ejic.200700047, 2068-2071.

23. K. Boulahya, M. Parras and J. M. Gonzalez-Calbet, Chemistry-a European Journal, 2007, 13, 910-915.

24. S. B. Adler, Chemical Reviews, 2004, 104, 4791-4843.

25. M. Sánchez-Andújar and M. A. Señarís-Rodríguez, Zeitschrift Für Anorg. Und Allg. Chemie., 2007, 633, 18901896.

26. U.S.A. Pat., 1967.

27. J. Rodríguez-Carvajal, Physica B: Condensed Matter, 1993, 192, 55-69.

28. S. B. Adler, Solid State Ionics, 1998, 111, 125-134. 